\title{
Development of problem-based learning material for physics mathematics and its implementation
}

\author{
Pujayanto, Supurwoko, Y Radiyono and Delisma W A \\ Physics Education Department, Sebelas Maret University, \\ J1. Ir. Sutami 36A Kentingan Jebres Surakarta 57126, INDONESIA \\ E-mail: pujapujayanto@ymail.com
}

\begin{abstract}
The research aims to develop Problem Based Learning material teaching of Mathematics Physics and to know the effect on the cognitive capability of undergraduate students. The research uses development method of Borg and Gall. There are ten steps such as data collection, planning, product drafting, pretest, pretest revise 1, main test, main test revise 2, posttest, final revision, and dissemination and implementation. The data collection uses questionnaire and cognitive test which will support the qualitative data. The result shows that the criterion of developing problem-based learning teaching materials is 5 level category when $43.33 \%$ respondents rate 5 level category and the others give 4 level category. Furthermore, students which use the materials increased and the most of the students have acquired cognitive value exceeds the value of minimum completeness criteria.
\end{abstract}

\section{Introduction}

Physics is considered as science or the most fundamental science because it is the basis of all other fields of science. Physics is a part of the development of science and technology because it is studying about natural phenomena in the form of matter within the scope of space and time. To be able to contribute to the development of science and technology and to understand the dynamic nature required mastery and understanding of the concepts of fundamental physics. The mastery of physics concepts steady, either natural phenomena or problems encountered, can be understood, analyzed, and interpreted correctly so that the information or problems solving can be justified scientifically. However, many physics problems encountered can't be resolved only on the basis of theoretical physics concept, but need help to solve mathematical problems that are encountered [1].

Mathematics Physics as an obligatory lesson for students university in Physics Education gives the basic of mathematics analysis in physics problems. In the Physics Education UNS, Mathematics Physics lecturing is given in 9 (nine) credits and distributed in semester II, III, and IV. The point of this lesson is designed for undergraduate students and set to give a technically understanding of mathematics analyze of physics concept [2]. Mathematics Physics develops the competent of quantitive analysis thinking based on logical mathematics reasoning when solving the physics problems [3]. 
One example of topics that require the ability physics concepts of mathematical analysis is the determination of the moment of inertia of objects. In general, the mass of an object is expressed as $M$, Massa broad elements dense mass $M \sigma(x, y)$ in the region $\mathrm{R}$ in the field - $\mathrm{xy}$, expressed by

$$
M=\iint_{R} \sigma(x, y) d x d y
$$

Mass of the object in space $M$ density areas -xyz in G space, expressed by:

$$
M=\iiint_{G} \rho(x, y, z) d x d y d z
$$

It is known that the coordinates of the center of mass of the object of mass $M$ are expressed as:

$$
\bar{x}=\frac{\int x d m}{\int d m}=\frac{\int x d m}{M}
$$

Coordinates of the center of mass of elements extents $(\bar{x}, \bar{y})$ mass dense $\sigma(\mathrm{x}, \mathrm{y})$, where $\mathrm{x}$ and $\mathrm{y}$ components as follows:

$$
\bar{x}=\frac{\iint_{R} x \sigma(x, y) d x d y}{\iint_{R} \sigma(x, y) d x d y}, \overline{\mathrm{y}}=\frac{\iint_{R} y \sigma(x, y) d x d y}{\iint_{R} \sigma(x, y) d x d y}
$$

Coordinates of the center of mass with density homogeneous area elements:

$$
\bar{x}=\frac{\iint_{R} x d x d y}{\iint_{R} d x d y}, \bar{y}=\frac{\iint_{R} y d x d y}{\iint_{R} d x d y}
$$

Coordinates of the center of mass $(\bar{x}, \bar{y}, \bar{z})$ element space density $\rho(x, y, z)$ is

$$
\iiint x \rho(x, y, z) d x d y d z \quad \text { and } \quad \iiint y \rho(x, y, z) d x d y d z
$$

The moment of inertia of an object within 1 from the axis of rotation is expressed as:

$$
I=\int l^{2} d M
$$

So that the moment of inertia of an area element of the rotary axis x-axis and y-axis is expressed as

$$
\begin{aligned}
& I_{x}=\int y^{2} d M=\iint_{A} y^{2} \sigma(x, y) d x d y \\
& I_{y}=\int x^{2} d M=\iint_{A} x^{2} \sigma(x, y) d x d y
\end{aligned}
$$

Against the $z$-axis element within the mass is $\sqrt{x^{2}+y^{2}}$, so that the moment of inertia of the rotary axis is the z-axis are:

$$
I_{y}=\int x^{2} d M=\iint_{A}\left(x^{2}+y^{2}\right) \sigma(x, y) d x d y
$$




$$
I_{z}=I_{x}+I_{y}
$$

The phrase above is called perpendicular axis theorem. It also applies parallel axis theorem, that the moment of inertia on the axis parallel to the first, the distance $d$ of the center of mass is expressed as

$$
I=I+M d^{2}
$$

Basically, text books of Mathematics Physics which is used as a basic book to study mathematic physics are Mathematical Methods in the Physical Sciences that is written by Mary L. Boas in English. This book provides a technique of mathematics analysis for physical problems solving[4]. Unfortunately, look for another book which is written in Bahasa Indonesia by other lecturers is not complete as Mary L. Boas book. Besides that, these books do not have enough material that can be presented. The mentioned books also still tend to theoretic so that the student keep using Mary L. Boas in English to find the problems solution that is faced. In other side, students in university are unusual to read English language literature even though they have been trained for it in English for Physics I and English for Physics II. This condition causes them difficulty to understand the material. Therefore, it is necessary to develop a physics teaching material that can be used as one of the references for students in the university of Indonesia to make them easy to understand the mathematics-physics. The notion that teaching material is different with text book or module [6].

Many types of research conducted in the study with problem solution training. This study model also is known as problem-solving or problem-based learning (PBL). Studying with problem solving can measure the ability of metacognition and undergraduates concept comprehension [6]. The research about "The Influence of Problem Solving on Studying Effectiveness in Physics" told that the effectivity of student's study is better if use problem solving [7]. Besides that, problem-based learning gives the positive impact for students. Students' ability in cognitive are better than before [8].

One of materials teaching that can be developed is a module. Material teaching of the module has superiority with some characteristics. For the student, this mathematics physics module is expected able to assist student university to understand mathematics physics better. Research shows that module usage improve students comprehension ability better significantly and it could be obtained by student university who use the module with Self-Regulated Learning (SRL) [9]. Other research about the development of Module in Physics Education shows that lecturing module that is developed can be executed very good, increase the activity of student's by them selves, complete of purpose mastery learning, and students give a positive response to the module content and the lecturing[10]. Another research about the development module of physics shown that through targeted teaching strategies in particular explicitly with the module[11]. So that it is important to develop module teaching material that follows the characteristic of mathematics physics and gives various training of physics problems solution. 


\section{Methods}

The method used in this research is the development of a model based on Borg \& Gall. The product being developed is the Problem Based Learning materials teaching for Mathematical Physics II. Borg and Gall (1989) suggested that there are ten stages in the implementation of development research strategy. Stage 1 to 7 is the stage of product development; such as the material teaching of problem-based learning for Mathematics Physics. While the stage 8 to 10 is a stage of implementation, is the application of the results of the development of materials teaching for Mathematics Physics in real lectures in class. Procedures for implementing this research can be seen in Figure 1. Data consist of two types; there are assessment data the development of teaching materials and data from the implementation of teaching materials. The instrument used in the development stage is feasibility questionnaires of teaching materials. Feasibility questionnaires of teaching materials are prepared to the validator and students. This instrument is used to determine the feasibility of teaching materials as seen from the content of the feasibility component and presentation (modification of BSNP). In this research, the data obtained during the development stage is a feasibility data of teaching material. Variable feasibility of teaching materials developed has been prepared based on the feasibility criteria of the content and presentation components (by modification) as shown Table 1.

Table 1. Assessment criteria

\begin{tabular}{cc}
\hline Interval Value & Category Level \\
\hline $\mathrm{Mi}+1,5 \mathrm{Sbi}<\mathrm{X}$ & 5 \\
$\mathrm{Mi}+0,5 \mathrm{Sbi}<\mathrm{X} \leq \mathrm{Mi}+1,5 \mathrm{Sbi}$ & 4 \\
$\mathrm{Mi}-0,5 \mathrm{Sbi}<\mathrm{X} \leq \mathrm{Mi}+0,5 \mathrm{Sbi}$ & 3 \\
$\mathrm{Mi}-1,5 \mathrm{Sbi}<\mathrm{X} \leq \mathrm{Mi}-0,5 \mathrm{Sbi}$ & 2 \\
$\mathrm{X} \leq \mathrm{Mi}-1,5 \mathrm{Sbi}$ & 1 \\
\hline
\end{tabular}

Where :

$\mathrm{X}=$ score of respondents

$\mathrm{Mi}=$ mean ideal

Sbi $=$ standard deviation of the ideal

$\mathrm{Mi}=1 / 2$ (the highest ideal score + the lowest ideal score)

Sbi $=1 / 6$ (the highest ideal score - the lowest ideal score) 


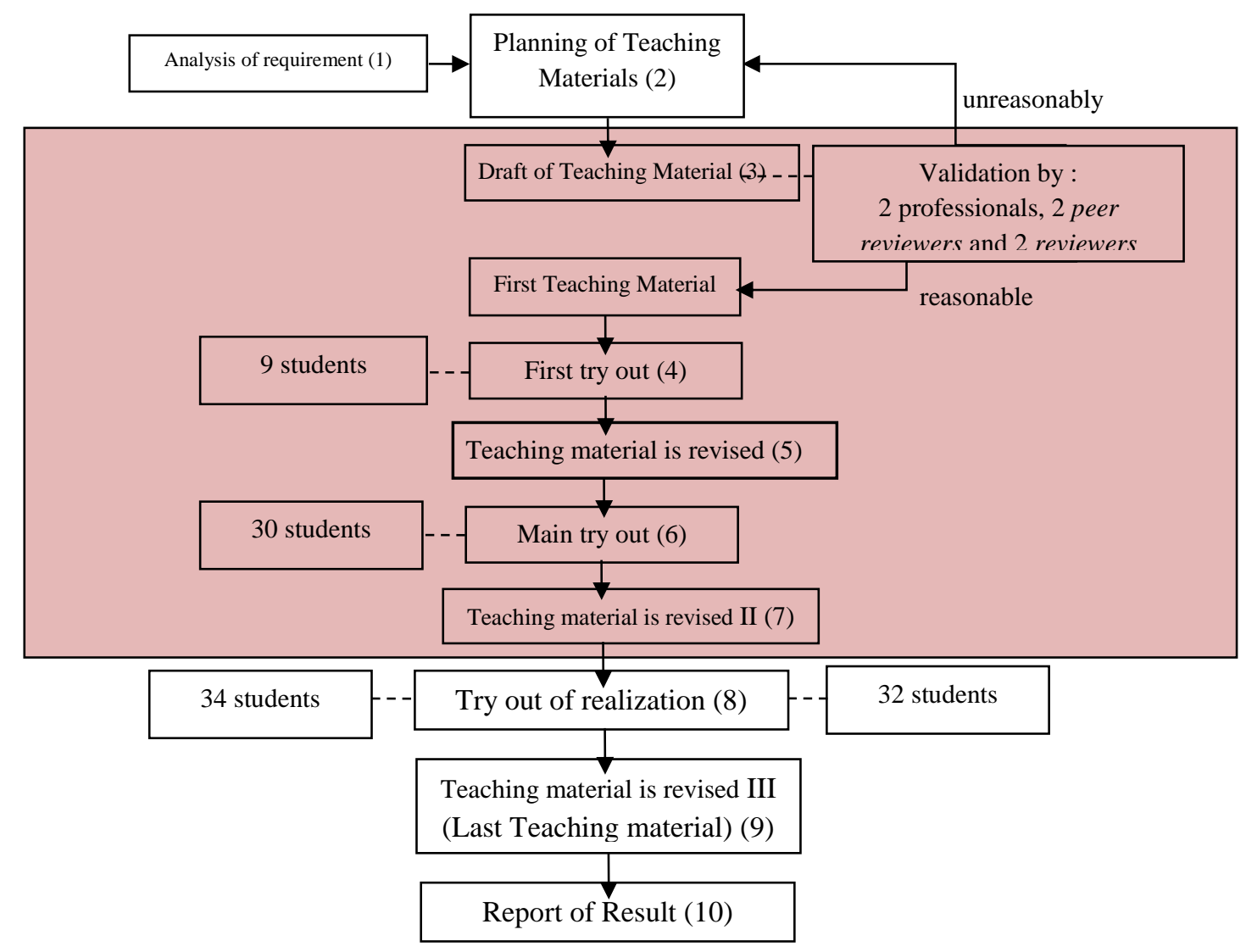

Figure 1. Design of Procedure Development

\section{Results and Discussion}

\subsection{Result of Validation Teaching Material}

Learning module was developed based on the sequence of mathematical physics concepts. Learning module is built systematically and should follow the principle idea first and name afterward'[13]. Based on the questionnaire of the validator (experts, reviewers and peer reviewers) it shows that the teaching material of problem-based learning for Mathematical Physics II developed has high-level category. A total of $83.33 \%$ validator is from an expert I and II, the reviewer I, peer reviewers I and II rate 5 category level and $16.67 \%$, is a reviewer II rate as 4 category level. This shows that all the validators agreed that the teaching materials of problem-based learning for Mathematical Physics II has been prepared for the test stage with suggestions and comments are used as materials to revise teaching materials.

Based on validator's suggestions and comments, teaching material of problem-based learning for Mathematical Physics revised with uniform symbols and notations between chapters. This is done at the beginning of the chapter, as in the purpose of learning between chapters 1, 2, 3 and 4 formatting uniform, then the symbols are initially between the symbol on the information originally written in lowercase, while the image is written with a capital letter, after receiving this advice symbol then homogenized with small letters. In addition, some images are initially in the form of scanned images and then clarified by creating their own images to the image can be made. 
Revisions are also made in part to give captions, improvements to the numbering of formulas and in writing about the exclamation point. Researchers also made materials to make revisions. Researchers then replace the exclamation mark (!) with a dot on the issues presented. In addition, the teaching materials also added some examples of questions on the advice of the reviewer.

\subsection{Result of First Tries Out}

First Try Out conducted on 9 students who have taken courses Mathematical Physics II. The results of the first try out are presented in Table 2. Based on Table 2, shown that a total of $55,56 \%$ rate 5 category level and $33,33 \%$ rate as 4 category level. Revisions were made starting from the justification writings typo, giving space writings, fixing arrangement the layout the reference list according to alphabet letters, give information source for some the images and improve the page numbering on teaching materials. For comments and suggestions to use the font variations, writing formulas with letters upright did not do by researchers because this suggestion was not included in feasibility aspect and presentation developed teaching material. The next revision is to add keywords to each chapter and added problems at the start of the material because in accordance with the developed teaching materials there is teaching material of problembased learning that will encourage students to analyze the problem before studying a concept of matter.

Table 2. Summary of first try out result

\begin{tabular}{cccc}
\hline Category Level & Grup Score & Frequency & Percentage \\
\hline 5 & $\mathrm{X}>97,5$ & 5 & $55,56 \%$ \\
4 & $82,5<\mathrm{X} \leq 97,5$ & 3 & $33,33 \%$ \\
3 & $67,5<\mathrm{X} \leq 82,5$ & 1 & $11,11 \%$ \\
2 & $52,5<\mathrm{X} \leq 67,5$ & - & - \\
1 & $\mathrm{X} \leq 52,5$ & - & - \\
\hline
\end{tabular}

\subsection{Result of Main Tries Out}

The main try out conducted on 30 students who are taking courses Mathematical Physics II. The results of the main try out are presented in Table 3. Based on Table 3, shown that a total of $43,33 \%$ rate 5 category level and 56,67\% rate as 4 category level. From the comments and suggestions of the main try out the result, not all of the comments and suggestions made as material revision. Revisions were made to suggestions and comments when necessary in the development of this teaching material. Revisions were made at the table, is to provide a source for the tables presented, adding examples of problems in accordance with the material. For suggestions and comments relating to the image, not be revised because the image is in conformity with the material presented. 
Tabel 3. Summary of main try out result

\begin{tabular}{cccc}
\hline Category Level & Grup Score & Frequency & Percentage \\
\hline 5 & $\mathrm{X}>97,5$ & 13 & $43,33 \%$ \\
4 & $82,5<\mathrm{X} \leq 97,5$ & 17 & $56,67 \%$ \\
3 & $67,5<\mathrm{X} \leq 82,5$ & - & - \\
2 & $52,5<\mathrm{X} \leq 67,5$ & - & - \\
1 & $\mathrm{X} \leq 52,5$ & - & - \\
\hline
\end{tabular}

\subsection{Result of Implementation Tries Out}

The implementation tries out was conducted to determine the effect of the implementation teaching materials developed for the cognitive abilities of students. Assessment teaching material usage is measured by comparing the learning outcomes of students in lectures using teaching materials of problem-based learning and without teaching materials of problem-based learning [14]. A class using teaching materials of problem-based learning carried on material Multiple Integral, while the lectures without teaching materials of problem-based learning carried on the material of Partial Differential. At each end of the course conducted tests to determine the cognitive abilities of students.

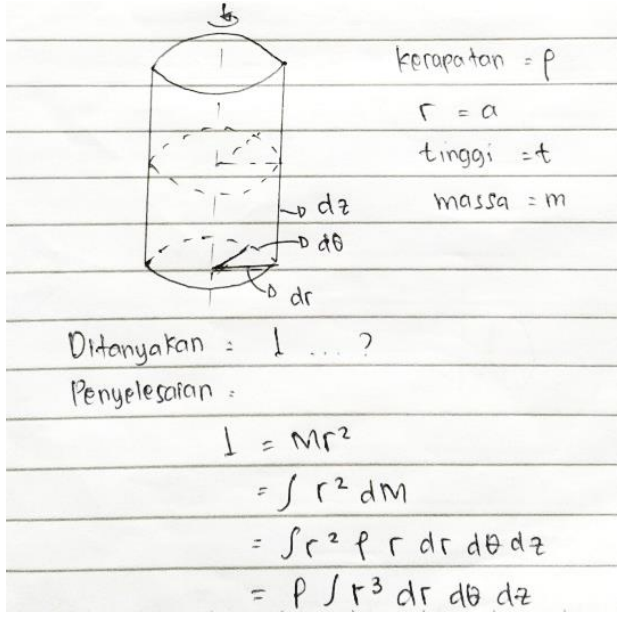

(a)

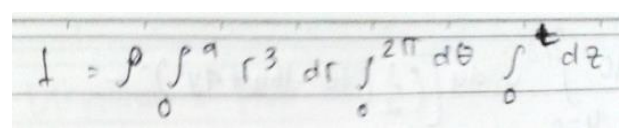

(b)

Figure 2. a) The results of visualization problems, (b) the results of the determination of the boundary integral

The implementation results in Figure 2 (a) that there is an increase in visualizing the problems in the field of coordinate / image so that the ability of delimitation inetgral also increased. Students have had the ability to determine the boundary integral previously students had difficulty in determining the boundary integral known from Figure 2 (b). From the analysis of the cognitive test results, obtained by the average value of students increased and the most of the students have acquired cognitive value exceeds the value of minimum completeness criteria. This shows that teaching materials of problem-based learning with the module in the learning effect on the cognitive abilities of students[15] [16]. 


\section{Conclusion}

Based on research, it can to be concluded that the teaching material of problem-based learning for Mathematics Physics meets high-level category is 5. From the result of main try out as the last step of development teaching material is obtained $43,33 \%$ responded evaluates for 5 category level. Teaching material of problem-based learning that is developed can increase the cognate ability of the student. From the result of try out of realization is obtained that average value of student is an increase. The matter that can be suggested, especially the result of research year I am development of teaching material of problem-based learning for Mathematics Physics II is as followed for the next research development of teaching material for Mathematics Physics can be applied to Mathematics Physics I and Mathematics Physics II. Teaching material of Mathematics Physics can be applied as alternative teaching material by the lecturer for studying in university. A student can use teaching material of Mathematics Physics as one of studying resource so they get easiness to study actively and autodidact.

\section{Reference}

[1] James M F et al 2014 Rep. Prog. Phys. 77032401

[2] I T Koponen et al 2004 The role of physics departments in developing student teachers' expertise in teaching physics Eur. J. Phys. 25645

[3] Frits F M D M et al 2004 How to encourage university students to solve physics problems requiring mathematical skills: the adventurous problem solving' approach Eur. J. Phys. 2551

[4] Boas M L 1983 Mathematical Methods in the Physical Sciences, second edition (Singapore)

[5] Panen P and Purwanto 2005 Applied Approach: Penulisan Bahan Ajar (Jakarta: Dikti)

[6] Mariati P S 2012 Jurnal Pendidika Fisika Indonesia 8 152-160

[7] Ganina S and Voolaid H 2011 The Influence of Problem Solving on Studying Effectiveness in Physics 80-92

[8] Atan H, Sulaiman F, and Idrus R M 2005 International Education Journal 6 430437

[9] Ellianawati and S Wahyuni 2012 Jurnal Pendidikan Fisika Indonesia 8 33-40

[10] Mulyanratna M, Mulyaningsih S and Sunarti T 2011 Proc. Seminar Nasional Penelitian (Yogyakarta: Fakultas MIPA Universitas Negeri Yogyakarta)

[11] M Hill et al 2015 How online learning modules can improve the representational fluency and conceptual understanding of university physics students Eur. J. Phys. 36045019

[12] Samsudi 2006 Desain Penelitian Pendidikan (Semarang: UNNES Pres)

[13] Kaarle K S 1998 Teaching Introductory Physics Eur. J. Phys. 19

[14] $\mathrm{Hu}$, Dehui and Rebello, N. Sanjay 2013 Understanding student use of differentials in physics integration problems Phys. Rev. ST Phys. Educ. Res. 9020108 
[15] T Sujarittham et al 2016 Developing specialized guided worksheets for active learning in physics lectures Eur. J. Phys. 37025701

[16] Jim M and Pamela A K 2001 The teaching and learning of physics, in Jere Brophy (ed.) Subject-specific instructional methods and activities Advances in Research on Teaching $8215-238$ 